\title{
Meslek Etiği Dersinin Öğrencilerin Hile Karşısındaki Tutumları ve Raporlama Eğilimleri Üzerindeki Etkisi
}

\author{
Hüseyin TEMIZ \\ Sorumlu Yazar: Bozok Üniversitesi İIBF, \\ huseyintemiz1@hotmail.com \\ Tansel HACIHASANOĞLU \\ Bozok Üniversitesi IIIBF \\ tanselh@gmail.com \\ Nurettin ÖZDEMIR \\ Bozok Üniversitesi, SBE Işsletme Bölümü \\ nurettin66ozdemir@hotmail.com
}

\begin{abstract}
$\ddot{O} \mathbf{z}$
Meslek etiği dersi ve dersi alan öğrenciler üzerindeki etkileri farklı disiplinler açısından literatürde incelenen bir konudur. Yaşanan ekonomik skandallar meslek etiği konusunun güncelliğini korumasına neden olmaktadır. Bu çalışmanın amacı, meslek etiği dersinin öğrencilerin belirli senaryolar karşısındaki etik değerlendirme ve raporlama eğilimleri üzerindeki etkilerinin incelenmesidir. Bu kapsamda 170 işletme bölümü öğrencisine anket uygulanmıştır. Öğrenciler meslek etiği dersi alan ve almayan öğrencilerden oluşmaktadır. Elde edilen bulgular üç başlık altında ifade edilebilir. Birincisi, meslek etiği dersi alan öğrencilerin almayan öğrencilere göre etik değerlendirmeleri ve raporlama eğilimleri daha yüksektir. İkincisi, kız öğrencilerin belirli senaryolarda erkek öğrencilere göre etik değerlendirmeleri ve raporlama eğilimleri daha yüksektir. Üçüncü ve son olarak, öğrencilerin bir senaryoyu etik dışı değerlendirmeleri ve bu senaryoları raporlama eğilimleri arasında anlamlı ilişkiler tespit edilmiştir.
\end{abstract}

Anahtar Kelimeler: Meslek Etiği, Etik Değerlendirme, Raporlama Eğilimi

Jel Kodu: M40, M42

The Effects Of Business Ethics Course On Students' Fraud Attitudes And Reporting Tendencies*

\begin{abstract}
Business ethics course and its effects on students' attitudes is a subject that investigated by different disciplines in literature. The economic scandals encountered induce to keep up-to-date of business ethics. The aim of this study is to investigate effects of business ethics course on students' ethical assessment and reporting tendency in view of given scenarios. Within this scope, a questionnaire was applied to 170 business administration students who take and do not take the course. Obtained results can be stated under three topics. First, students who take business ethics course have higher ethical assessment and reporting tendencies than non-taking students. Second, female students have higher ethical assessment and reporting tendencies than boys in certain scenarios. Last, significant relationship has been found between students' assessment of a scenario as unethical and their tendencies to report these scenarios.
\end{abstract}

Keywords: Business Ethics, Ethical Assessment, Reporting Tendency

Jel Codes: M40, M42

Extended abstract is presented at the end of the article.

Atıfta bulunmak için/Cite this paper:

Temiz, H., Hacıhasanoğlu, T. ve Özdemir, N. (2018). Meslek etiği dersinin öğrencilerin hile karşısındaki tutumları ve raporlama eğilimleri üzerindeki etkisi. Çankırı Karatekin Üniversitesi İBF Dergisi. 8 (2), 137-155. 


\section{Giriş}

İşletmeler tarafından hazırlanan ve finansal bilgi kullanıcılarının hizmetine sunulan mali tabloların, güvenilir ve gerçeğe uygun bir şekilde sunulması gerekmektedir. Ancak böylesi bir sunum, çeșitli nedenlerden dolayı çoğu zaman mümkün olmamaktadır. Bu durumun nedenleri arasında en önemli yeri, meslek etiği ve hile algısı almaktadır. Gerek yöneticilerin gerekse işletme çalışanlarının meslek etiği ve hile ile ilgili bakış açıları finansal tabloların olduğundan farklı sunulmasına sebep olmaktadır. Özellikle 2000'li yılların başında muhasebe skandalları sonucunda yaşanan şirket iflasları, muhasebecilik mesleğinde etik ve hile anlayışının sorgulanmasına ve yeniden gözden geçirilmesine neden olmuştur. Toplumun birçok kesimini yakından ilgilendiren finansal bilgilerin, etik kurallar çerçevesinde ve hile anlayışından uzak bir şekilde sunulabilmesi güvenilir bir sunum için en önemli kriterdir. Muhasebe sisteminin, ihtiyaç duyulan finansal bilgileri güvenilir bir şekilde sunma görevi göz önüne alındığında, meslek etiği ve hile kavramlarının önemi daha iyi anlaşılmaktadır.

İşletme bünyesinde yapılan hileli raporlama eyleminden işverenler, çalışanlar, yatırımcılar, tedarikçiler, müşteriler ve kamu kurumları etkilenmektedir. Yapılan hile türüne göre olumsuz etkilenen grup zaman zaman değişmektedir. Örneğin çalışanlar tarafından yapılan hileli işlemlerden yöneticiler olumsuz etkilenirken, yöneticiler tarafından yapılan hileli işlemlerden ise yatırımcılar ve devlet etkilenebilmektedir. Ama hangi hile türü yapılırsa yapılsın, yapılan hile sonucunda bir taraf kendine çıkar sağlarken, diğer taraf da zarara uğratılmaktadır.

Yapılan hileli işlemlerin ortaya çıkardığı finansal etkilere bakıldığında, çalışanlar tarafından yapılan hileler ile işletme sahibi ve yöneticiler tarafından yapılan hileler arasında önemli farklar ortaya çıkmaktadır. Hileyi yapan kişinin işletmedeki konumu ile hileli işlemin verdiği zarar arasında doğrusal bir bağlantı vardır. Uluslararası Suistimal İnceleme Uzmanları Birliği (Association of Certified Fraud Examiners, ACFE) tarafindan 2016 yilında yapılan bir araştırmada, hilelerin sadece \%18,9'unun şirket sahipleri ve üst düzey yöneticiler tarafından yapılmasına rağmen ortaya çıkardıkları zarar olay başına $703.000 \$$ olarak tespit edilmiştir. Aynı araştırmada, çalışanlar tarafından yapılan hilelerin toplam hileler arasında \%40,9'luk bir orana sahip olmasına rağmen, ortaya çıkardıkları zarar olay başına sadece 65.000 \$ olarak hesaplanmıştır (ACFE, 2016, s. 5). $\mathrm{Bu}$ araştırma sonuçlarından da görüldüğü üzere, hileyi yapan kişinin işletmedeki konumu ile ortaya çıkardığı zarar arasında bir paralellik söz konusudur.

Ekonomik skandalların ve söz konusu olumsuz çıktılarının en aza indirgenmesi amacıyla çeşitli çalışmalara yapılmaktadır. Bu kapsamda yapılan çalışmalar, yasal düzenlemelerin yanı sıra temelinde insan olan faaliyetlerin etik değerlere bağlı kalınarak yapılmasını sağlayan düzenlemeleri içermektedir. Bu noktada yapılan akademik çalışmalarla birlikte ulusal ya da uluslararası politikalar eğitim 
aşamasında etik konusuna dikkat çekmektedir. Buradaki temel bakış açısı eğitim sürecinde verilen etik dersinin öğrencinin etik değerleri üzerinde etkili olacağ 1 ve eğitim hayatını tamamlayan ve artık bir profesyonel olan öğrencinin karar sürecinde aldığı etik dersi etkilerini yansıtacağıdır (Jennings ve Marriott, 2013).

Etik, genel olarak ilkeler ve ahlaki değerler seti olarak tanımlanabilir (Yarahmadi ve Bohloli, 2015, 2). Muhasebe uygulamalarını gerçekleştiren kişi/kişiler de başlangıç aşamasında topluma karşı olan sorumluluğu kabul etmiş olmaktadır. Muhasebeciler, işletmelerin finansal raporlarını güvenilir hale getiren kişilerdir. $\mathrm{Bu}$ nedenle söz konusu muhasebecilerin almış oldukları eğitim de önemli hale gelmektedir. Muhasebecilerin mesleki uygulamalardaki etik farkındalıkları ve ahlaki ilkeleri de muhasebe etiği olarak tanımlanabilir (Ahmad ve Ahmed, 2017, 2).

Ekonomik skandallar ve ortaya çıkardığı olumsuz sonuçları değerlendirildiğinde önem kazanan etik değerleri yüksek muhasebeci ihtiyacı, etik konularının sınıf ve müfredat kapsamında tartışılmasına neden olmuştur. Genel olarak sınıf ve müfredata etik eğitiminin dahil edilmesinin öğrencilerin etik açıdan gelişim göstermelerine yardımcı olacağ gerekliliği literatürde yer alan çalışmalarda ifade edilmiştir (Adkins ve Radtke, 2004; Dellaportas vd., 2006; McPhail ve Walters, 2009) . Bu doğrultuda bu çalışmanın amacı, lisans eğitiminde "meslek etiğii" dersi alan ve almayan öğrencilerin etik senaryolar karşısındaki davranışlarının ve raporlama eğilimlerinin farklılaşıp farklılaşmadığının incelenmesidir. Diğer bir ifade ile lisans düzeyinde verilen meslek etiği dersinin öğrencilerin etik farkındalık düzeyleri ve söz konusu senaryoları raporlama eğilimleri üzerindeki etkisi olup olmadığına çalışma kapsamında cevap aranmaktadır. Çalışmanın birinci bölümünde muhasebecilik mesleğinde etik değerler ile ilgili kavramsal çerçeveye, ikinci bölümünde meslek etiğinin muhasebe eğitimindeki yeri ve önemine ilişkin yapılan çalışmalara, üçüncü bölümünde ise çalışmada uygulanan araştırmaya ilişkin veri, yöntem ve bulgulara ilişkin hususlar raporlanmıştır. Dördüncü ve son bölümde de, sonuç ve değerlendirmelere yer verilerek çalışma tamamlanmıştır.

\section{Kavramsal Çerçeve}

Çalışma kapsamında sıkça kullanılan etik, meslek etiği, muhasebe meslek etiği, hile, mesleki hile ve hile türleri gibi temel kavramların açıklanması yerinde olacaktır.

\subsection{Etik, Meslek Etiği ve Muhasebe Meslek Etiği}

Etik kavramı Türk Dil Kurumu'nda, "felsefenin bir dalı olarak ödev, yükümlülük, sorumluluk ve erdem gibi kavramları analiz eden, doğruluk veya yanlışlık ile iyi veya kötüyle ilgili ahlaki yargıları ele alan, ahlaki eylemin doğasını soruşturan ve iyi bir yaşamın nasıl olması gerektiğini açıklamaya çalışan bir alan” şeklinde 
tanımlanmıştır. Tanımdan da anlaşılacağı üzere etik, bir davranışın doğruluğu, yanlışlığı, iyiliği veya kötülüğü ile ilgilenmektedir. Meslek etiği ise, herhangi bir meslek grubu ile ilgili toplum yararı gözetilerek oluşturulan ve korunan ilkelerdir. $\mathrm{Bu}$ ilkeler, konulan kurallara uyulması hususunda meslek mensuplarına emir veren, meslek mensuplarını bu kurallara uymaya zorlayan, meslek mensuplarının kişisel eğilimlerinin önüne geçen, aykırı davranışta bulunan meslek mensuplarını meslekten dişlayan ve meslek içi rekabeti düzenleyen kurallar bütünüdür (Yıldız, 2011, s. 160). Her meslekte olduğu gibi muhasebecilik mesleğinde de etik kuralların varlığı çok önemlidir. Muhasebecilik mesleğinde etik, finansal bilgilerin tarafsız, doğru, dürüst, güvenilir ve sorumluluk bilinciyle sunulmasını ifade etmektedir. Muhasebecilik mesleğinin yapısı gereği, gerek mali nitelikteki işlemlerin konu alınması, gerekse etki alanının çok geniş olması nedeniyle bu alanda hazırlanan etik kurallar ayrı bir öneme sahip olmaktadır.

\subsection{Hile, Mesleki Hile ve Hile Türleri}

Çalışmanın diğer bir boyutu olan hile ise Türk Dil Kurumu'nda, "birini aldatmak, yanıltmak için yapılan düzen, dolap, oyun, ayak oyunu, alavere dalavere, desise, entrika" ve "çıkar sağlamak için değersiz bir şeye değer katma" olarak tanımlanmıştır. Hile, tanımdan da anlaşılacağı üzere istenerek ve kontrollü bir şekilde yapılmaktadır. Bu yönüyle hile ile hata birbirinden ayrılmaktadır. Çünkü hata, istem dışı ve kontrolsüz bir şekilde yapılmaktadır. Hile kasıtlı bir şekilde yapılırken, hatalar kasıt içermezler. Hile yapan kişi kendine çıkar sağlarken, hata yapan kişi için böyle bir durum söz konusu değildir. Hilenin mesleki bir alanda yapılması sonucu mesleki hile kavramından bahsedilir. Mesleki hile, "bir kimsenin, mesleğini, işveren firmanın kaynaklarını veya varlıklarını kasıtlı olarak kötüye kullanma yoluyla, şahsi zenginleşme için kullanması" olarak tanımlanmıştır (ACFE, 1996, s. 2). Mesleki hile çalışanlar tarafından yapılabileceği gibi, yönetici ve işletme sahipleri tarafından da yapılabilmektedir. Kim tarafindan yapılırsa yapılsın yapılan hile sonucunda mutlaka birileri zarara uğrarken, birileri de kendilerine çıkar sağlamaktadırlar.

Hile türleri çalışan hileleri, yönetim hileleri, yatırım hileleri, satıcı hileleri ve müşteri hileleri olmak üzere beşe ayrılır. Çalışan hileleri, işletme çalışanlarının doğrudan veya dolaylı olarak işverenden çalması şeklinde gerçekleşir. Bu hile türünde zarara uğrayan taraf işverendir. Yönetim hilelerinde, üst yönetim ekibi genellikle finansal tabloları olduğundan farklı gösterirler. Bu hile türünde zarara uğrayan taraf, tüm finansal tablo kullanıcılarıdır. Yatırım hilelerinde, yatırımcıların hileli yatırımlara para yatırmaları sağlanır. Bu hile türünde zarar uğrayan taraf yatırımcılardır. Satıcı hilelerinde, satıcılar ya fiyatları şişirirler ya da parası ödenmiş malların teslimini yapmazlar. Bu hile türünde, mal veya hizmeti satın alan işletmeler zarara uğratılırlar. Müşteri hileleri ise, müşterilerin yanıltıcı bilgiler vermesi sonucu satıcıların aldatılması şeklinde gerçekleşir. $\mathrm{Bu}$ hile türünde de, mal veya hizmet satan işletmelere zarara uğratılırlar. 


\section{Meslek Etiğinin Muhasebe Eğitimindeki Yeri Ve Önemi}

Muhasebe eğitiminde meslek etiğinin yerini ve etkisini belirlemeye yönelik yapılmış çalışmalar, genel olarak öğrencilere etik konuları içeren ve muhtemelen yasadışı veya sorgulanması gereken davranışların yer aldığı senaryoların ya da olayların verilmesi yoluyla kurgulanmıştır. Daha sonra uygun etik gereklilikler sunularak ya da örneklem grubundaki katılımcıların etik eğitimi alıp almadıklarına göre gruplandırılarak senaryo ve örnek olaylar karşısındaki davranışları ekseninde meslek etiği eğitiminin davranışlar üzerindeki etkisi değerlendirilmektedir. Ayrıca davranışları şekillendiren demografik ve kültürel özellikler de çalışmalar da incelenmiştir.

Hiltebeitel ve Jones (1992) çalışmasında iki farklı üniversitede etik farkındalık sağlayan on bir muhasebe dersinin öğrencilerin etik farkındalık düzeylerine olan etkileri incelenmiştir. Çalışma kapsamında elde edilen sonuçlara göre öğrencilerin ders içeriklerine eklenen etik farkındalık uygulamalarından etkilendikleri belirlenmiştir. Etik farkındalık yaratan dersleri alan öğrencilerin çalışma kapsamında ifade edilen açıklama kuralı, altın kural ve profesyonel etik uygulamalarına daha bağlı oldukları ifade edilmiştir.

Ahmed vd. (2003) çalışmasında iş etiği kültürel ve kavramsal olarak incelenmiştir. $\mathrm{Bu}$ kapsamda farklı ülkelerdeki işletme bölümü öğrencileri iş hayatında karşılaşılan durumlara ilişkin etik algılarına sosyo-kültürel etkilerin olup olmadığı incelenmiştir. Elde edilen sonuçlara göre etik iş davranışlarının ne olduğu, ülkeler arasında farklılık göstermeden üzerinde hem fikir olunmuştur. Ancak katılımcıların etik dışı davranışlara olan tolerans düzeylerinin farklılaştı̆g tespit edilmiştir. Çalışmada söz konusu farklılıkların anlaşılmasında sosyokültürel boyutun etkisinin olduğu ifade edilmiştir.

Şımga-Mugan ve Önkol-Atay (2003), çalışmasında etik duyarlılıklar cinsiyete göre ölçülmüştür. Çalışmada cinsiyetin etik duyarlılık düzeyi üzerindeki etkileri işletme bölümü öğrencileri kapsamında test edilmiş ve cinsiyete dayalı bir farklılık olmadığ 1 tespit edilmiştir. Ayrıca erkek öğrencilerin kız öğrencilere daha katkı cezai uygulamaları onay verdikleri değerlendirilen çalışmada işletme senaryolarında cinsiyete bağlı farklılıkların olmadığı ifade edilmiştir.

Gill (2010) çalışmasında işletme öğrencileri üzerinde etik davranışların cinsiyete göre farklılaşıp farklılaşmadığı incelenmiştir. $\mathrm{Bu}$ kapsamda incelenen kız öğrencilerin erkek öğrencilere göre daha etik eğilimlere sahip oldukları tespit edilmiştir. Ayrıca etik karar verme sürecinde erkek öğrencilerin kız öğrencilere göre daha düşük çeşitlilik gösterdikleri sonucuna ulaşılmıştır.

Kurnaz ve Gümüş (2010) çalışmasında öğrencilerin eğitim gördükleri yıl kapsamında ele alınmıştır. Elde edilen bulguların üst sınıf öğrencilerinin alt sınıf ögrencilerine nazaran etik dışı davranışlara karşı daha hassas oldukları tespit 
edilmiştir. Ayrıca çalışmadan elde edilen sonuçlar öğrencilerin ekonomik temellere dayanan etik dışı davranışları diğer sebeplere dayanan etik dışı davranışlara göre daha az etik dışı değerlendirdikleri ifade edilmiştir.

Eweje ve Brunton (2010) çalışmasında 655 işletme bölümü öğrencisi üzerinde cinsiyet, yaş ve iş deneyiminin öğrencilerin etik muhakemeleri üzerinde bir etkisinin olup olmadığı incelenmiş̧ir. İşletme bölümü öğrencilerinin örneklem grubuna seçilme nedeninin geleceğin yöneticileri olma potansiyelleri olduğu ifade edildiği çalışmada kız öğrencilerin erkek öğrencilere göre daha etik davranışlar gösterdikleri sonucuna ulaşılmıştır. Çalışmada ayrıca yaşın etik farkındalık üzerinde etki olduğu, ancak bu etkinin her zaman olumlu yönde olmadığı belirtilmiştir. Deneyiminin de etik farkındalık üzerinde genel olarak pozitif etkisi olduğu çalışma kapsamında ifade edilmiştir.

Klimek ve Wenell (2011) çalışmasında etik eğitimini muhasebe eğitimi dahilinde alan ve ayrı zorunlu bir ders olarak öğrencilerin durumu karşılaştırılmıştır. Elde edilen sonuçlara göre ayrı zorunlu bir ders olarak alınan etik eğitimin, muhasebe dersi içerisinde verilen etik eğitiminden daha etkili olduğu ifade edilmiştir.

Liu vd. (2012) çalışmasında muhasebe dersinde etik eğitimi veriliş şekline yönelik sağlık ve hukuk alanlarındaki uygulamalar kapsamında öneriler sunulmuştur. $\mathrm{Bu}$ kapsamda muhasebe dersinde etik öğretiminin sağlık ve hukuk alanında etik eğitimine kıyasla daha az formal eğitim düzeyine sahip olduğu ve daha az işbirliğine yer verildiği belirtilmiştir. Söz konusu durumların da sağlık ve hukuk alanında verilen etik eğitimi alan öğrencilerin daha yüksek ahlaki bilişsel özelliklere sahip olmalarını sağladığı belirtilmiştir.

Dönmez ve Karausta (2011), çalışmasında olan öğrenciler geleceğin meslek mensupları olarak değerlendirilmiş ve hile algıları ve söz konusu hileli durumu raporlama eğilimleri incelenmiştir. Çalışma kapsamında yapılan incelemelerde öğrenciler cinsiyet, bölüm ve yıl kapsamında değerlendirilmiştir. Elde edilen sonuçlara göre öğrencilerin hileli olarak değerledikleri olaylar ve bu olayları raporlama eğilimleri arasında pozitif bir ilişki olduğu tespit edilmiştir. Öğrencilerin etik dışı davranış grubunda bulunan yolsuzluğu, finansal tablo hilesi ve varlık usulsüzlüğüne göre daha çok ciddiye aldıkları ifade edilmiştir. Ayrıca kız öğrencilerin erkek öğrencilere göre etik dışı davranışlara karşı daha hassas oldukları ve raporlama eğilimlerinin de yüksek olduğu değerlendirilmiştir.

Benzer bir sonuç da Hacıhasanoğlu ve Karaca (2015) çalışmasından elde edilmiştir. Bu çalışmada öğrencilerin hile algıları ve bu uygulamaları raporlama eğilimleri incelenmiş̧tir. Elde edilen bulgular öğrencilerin yolsuzluğu, finansal tablo hilesi ve varlık usulsüzlüğüne göre daha ciddiye aldıkları tespit edilmiştir. Ayrıca çalışmada öğrencilerin etik dışı değerlendirilen olayları tespit etme düzeyleri ve bu olayları raporlama eğilimleri arasında pozitif ilişki olduğu ifade edilmiştir. Çalışmada son olarak, kız öğrencilerin erkek öğrencilere göre etik dışı 
davranışlara karşı daha hassas oldukları ve bu davranışları raporlama eğilimlerinin de daha yüksek olduğu tespit edilmiştir.

Uyar vd., (2015) tarafından yapılan çalışmada, öğrencilerin etik algıları değerlendirilmiştir. Çalışma kapsamında öğrencilerin etik dersi alıp almamalarının etik değerlendirme düzeyleri üzerindeki etkisi incelenmiştir. Araştırmada ayrıca, meslek etiği dersi alan öğrencilerle almayanlar arasındaki etik algısında farklılık olup olmadığı araştırılmıştır. Elde edilen bulgulara göre öğrencilerin etik dış1 davranışları tespit edebildikleri, ancak etik dersi almış olmanın değerlendirmeler üzerinde bir etkisinin olmadığı görülmüştür.

Cameron ve O’Leary (2015) çalışmasında etik eğitimi almış son sınıf öğrencilerine senaryolar sunulmuştur. Bu senaryoların yarısında hem etik hem de yasal işlemlerin gerekmekte iken diğer yarısında yasal yönü olmayan yalnızca etik farkındalık düzeyi gerektiren işlemler yer almaktadır. Senaryolarla birlikte öğrencilere ek etik gereklilikleri de sunulmuştur. Elde edilen bulgulara göre, yasal ve etik olan olaylardaki öğrenci algısına ek etik gereklilikler bilgisi sunulmasının etkili olduğu sonucuna ulaşılmıştır. Yalnızca etik farkındalık gerektiren durumda ise ek etik gereklilik verilmesinin herhangi bir farklı davranışla neden olmadığ 1 ifade edilmiştir. Bu noktadan hareketle çalışmada etik açıdan doğru davranışın sağlandığ1 bir eğitim sisteminde muhasebe etik eğitiminin yeniden değerlendirilmesi önerilmiştir.

Çalışmalardan elde edilen bulgulardan yola çıkılarak genel olarak meslek etiği konusunun muhasebe derslerine entegre edilmesinin öğrenci davranışları üzerinde etkili olduğu değerlendirilmektedir. Yapılan değerlendirme çerçevesinde, eğitim aşamasında meslek etiğinin müfredata eklenmesinin gelecek dönemlerde ortaya çıkabilecek olumsuz sonuçların önlenmesinde etkili olabilecek bir yöntem olduğu düşünülebilir.

\section{Yöntem}

\subsection{Araştırmanın Amacı ve Kapsamı}

Öğrencilerin meslek etiği ve hile algıları ile ilgili anlayışlarını etkileyen birçok değişken söz konusudur. Bu değişkenlerde birisi de, lisans düzeyinde meslek etiği dersinde aldıkları eğitimdir. Ulusal ve Uluslararası düzeyde yapılan birçok çalışmada öğrencilerin aldıkları meslek etiği ile ilgili eğitimin, olumlu sonuçlar doğurduğu tespit edilmiştir (Klimek ve Wenell, 2011; Hiltebeitel ve Jones, 1992; Cameron ve O'Leary, 2015). Bu noktadan hareketle çalışmanın temel amacı, meslek etiği dersi alan öğrenciler ile bu dersi almayan öğrencilerin etik olaylar karşısında sergileyecekleri tutum ve davranışların farklılaşıp farklılaşmayacağını ortaya koymaktır. Öğrencilerin meslek etiği ve hile ile ilgili algılarının cinsiyete göre değişip değişmediği, öğrencilerin etik olaylar karşısında sergileyecekleri 
tutum ile bunun sonucunda gösterecekleri davranış arasında ilişki olup olmadığının belirlenmesi de çalışmanın diğer alt amaçları olarak belirlenmiştir.

\section{2. Örneklem ve Veri Toplama Yöntemleri}

$\mathrm{Bu}$ araştırma tanımlayıcı nitelik taşımaktadır. Araştırma kapsamına Bozok Üniversitesi İktisadi ve İdari Bilimler Fakültesi İşletme Bölümünde eğitim almakta olan öğrenciler alınmış ve anket yöntemi kullanılarak birincil veriler toplanmıştır. Çalışmanın finansal olaylar karşısında sergilenen tutum ve raporlama eğilimlerinin tespit edilmesi çerçevesinde yapılması nedeniyle, muhasebe alanında eğitim alan işletme bölümü öğrencileri hedef kitle olarak belirlenmiştir. Çalışmada en yüksek öğrenci sayısına ulaşabilmek amacıyla son sınıfta öğrenimlerine devam eden toplam 250 öğrenciye anket dağıtılmıştır. Dağıtılan anketlerin toplanması sonucunda ele geçen ve değerlendirmeye tabi toplam 170 anket analiz edilmiştir. İşletme bölümünde eğitim almakta olan 4. sınıf öğrencileri, meslek etiği ve hile ile ilgili algılarının ölçülmesi ve karşılaştırılması amacıyla iki farklı gruba ayrılmıştır. Birinci grupta son sınıfta öğrenim gören ve henüz meslek etiği dersini almayan öğrenciler yer almıştır. İkinci grupta ise meslek etiği dersini alan son sınıf öğrencileri yer almıştır. İkinci grupta yer alan öğrencilere öncelikle meslek etiği dersi kapsamında; muhasebe mesleği ile ilgili mevzuat, muhasebe mesleğinin konusu ve mesleğe giriş, mesleğin yürütülmesi, mesleğin temel kuralları, mesleğin yürütülmesi esnasındaki yasaklar, suçlar ve cezalar, muhasebe meslek etiği, mesleğin örgütlenmesi gibi konularda eğitimler verilmiştir. Verilen eğitimlerin yanı sıra öğrencilere tarihin en büyük muhasebe skandallarından biri olan Enron Vakası ile ilgili "Enron: The Smarteset Guys in the Room" adlı film izlettirilmiştir. Verilen eğitimler ve yapılan faaliyetler sonucunda meslek etiği dersini alan öğrencilerin meslek etiği ile ilgili bilinç sahibi olmaları sağlanmıştır. Bu süreç sonunda toplam uygulanan anket sayısından geri dönüşler ve uygun yapıya sahip olanların 170 adet olduğu tespit edilmiştir. 170 anketin $75^{\prime}$ i meslek etiği dersi alan öğrencilere ve 95'i ise meslek etiği dersi almayan öğrencilere aittir.

Öğrencilerin etik ve hile algısının ölçülmesi çerçevesinde yapılan bu çalışmada, Baird ve Zelin (2008) çalışmasına dayanan ve Dönmez ve Karausta (2011) ile Hacıhasanoğlu ve Karaca (2015) tarafindan Türkçeye çevrilen ölçek kullanılmıştır. Kullanılan ölçekte 6 adet senaryo yer almaktadır. Bu senaryolardan iki tanesi varlık usulsüzlügü, iki tanesi yolsuzluk ve iki tanesi de finansal tablo hilesi olarak tasarlanmıştır. Ölçekte yer alan senaryolar, çalışmaya uygun olacak şekilde güncellenmiştir.

Çalışmada ihtiyaç duyulan verilerin toplanması amacıyla öğrencilere uygulanan anket iki bölüm halinde oluşturulmuştur. Anketin birinci bölümünde öğrencilere ait demografik bilgiler kapsamında sadece cinsiyet ve meslek etiği dersi alıp almadığına dair verinin elde edilmesi amacıyla bu değişkenlerin yer aldığı bölüm yer almıştır. İkinci bölümde ise, öğrencilerin etik olaylar karşısında 
sergileyecekleri tutum ile bunun sonucunda gösterecekleri davranışın ölçülmesi amacıyla hazırlanan altı adet senaryo yer almıştır. $\mathrm{Bu}$ senaryoların her biri için öğrencinin ilgili olaya karşı tutumu ve raporlama eğilimi ölçülmeye çalışılmıştır. $\mathrm{Bu}$ ölçümün yapılabilmesi için de beşli likert ölçeği kullanılmıştır. Öğrencilerin senaryolara katılma derecelerini ölçmek amacıyla "1-Kesinlikle Katılmıyorum.... 5-Kesinlikle Katılıyorum” aralığında cevap vermeleri istenmiştir. Verilen cevap doğrultusunda öğrencilerin gösterecekleri raporlama eğilimlerinin ölçülmesi amaciyla da "1-Kesinlikle Rapor Etmezdim...5-Kesinlikle Rapor Ederdim" aralığında sorular yer almıştır.

\subsection{Araştırmada Test Edilecek Hipotezler}

$\mathrm{Bu}$ çalışmada meslek etiği dersi alan öğrenciler ile almayan öğrencilerin etik olaylar karşısında sergileyecekleri tutum ile bunun sonucunda gösterecekleri davranışın farklılaşıp farklılaşmadığı araştırılmıştır. Söz konusu değerlendirme kriteri literatürde yapılmış çalışma bulgularına dayanmaktadır (Klimek ve Wenell, 2011; Hiltebeitel ve Jones, 1992; Cameron ve O'Leary, 2015). Ayrica öğrencilerin etik olaylar karşısında sergileyecekleri tutum ve davranışların, cinsiyetlerine göre değişip değişmediğinin ölçülmesi de araştırılmıştır. Bu noktada da yine literatürde yapılmış benzer çalışmalara ait bulgu ve değerlendirmeler dikkate alınmıştır (Dönmez ve Karausta, 2011; Eweje ve Brunton, 2010; Gill, 2010; Hacıhasanoğlu ve Karaca, 2015). Bunların dışında öğrencilerin etik olaylar karşısında sergileyecekleri tutum ile bunun sonucunda gösterecekleri raporlama eğilimi arasında ilişki olup olmadığının tespit edilmesi de diğer bir araştırma konusu olarak belirlenmiştir. Araştırma kapsamında test edilecek hipotezler şunlardır:

$H_{1}$ : Meslek etiği dersi alan ögrenciler ile almayan öğrencilerin etik dışı olaylar karşısında sergileyecekleri tutum arasında farklılık vardır.

$\mathrm{H}_{2}$ : Meslek etiği dersi alan öğrenciler ile almayan öğrencilerin etik dışı olaylar sonucunda sergileyecekleri raporlama eğilimi farklılık gösterir.

$H_{3}$ : Öğrencilerin etik dışı olaylar karşısında sergileyecekleri tutum cinsiyetlerine göre farklılık gösterir.

$H_{4}:$ Öğrencilerin etik dışı olayları raporlama eğilimleri cinsiyetlerine göre farklılık gösterir.

$H_{5}$ : Öğrencilerin etik dışı olaylar karşısında sergileyecekleri tutum ile bunun sonucunda gösterecekleri raporlama eğilimi arasında anlamlı ilişki vardır.

\subsection{Verilerin Analizi ve Elde Edilen Bulgular}

Çalışma kapsamında Bozok Üniversitesi İktisadi ve İdari Bilimler Fakültesi İşletme Bölümü son sınıfta öğrenimlerine devam eden 250 öğrenciye anket dağıtılmıştır. Anket geri dönüşleri sonucunda söz konusu toplam anketten 170 adedinin analiz için uygun olduğu tespit edilmiştir. Değerlendirmeye alınan 170 anketin $75^{\prime}$ i inceleme döneminde meslek etiği dersi alan öğrencilere aittir. Kalan 
95 anket ise seçmeli ders olan meslek etiği dersini almayan grubu oluşturmaktadır. Ayrıca değerlendirmeye alınan 170 öğrencinin 80'nini erkek öğrenciler, 90’nını ise kız öğrenciler oluşturmaktadır.

Araştırma kapsamında elde edilen veriler SPSS paket programı aracılığıyla analiz edilmiştir. $\mathrm{Bu}$ araştırma kapsamında ilk olarak güvenilirlik analizi yapılmışıır. Öğrencilerin meslek etiği ile ilgili tutum ve davranışlarının ölçülmesi amacıyla altı senaryo ilişkili olduğu şekilde üç farklı sınıflandırmaya tabi tutulmuştur. Yapılan sınıflandırma sonucunda öğrencilerin varlık usulsüzlüğü, yolsuzluk ve finansal tablo hileleri ile ilgili verdikleri cevapların ortalamaları ve standart sapmaları hesaplanmıştır. Bu sayede her bir senaryo grubu için, öğrencilerin sergileyecekleri tutum ile bunun sonucunda gösterecekleri raporlama eğilimi ortaya konulmaya çalışılmıştır. Bu hesaplamaların sonucunda da, araştırma kapsamında kurulan hipotezlerin test edilmesi için varyans analizi yöntemlerinden Tek yönlü manova ve korelasyon analizi kullanılmıştır. Tek yönlü manova analizi birden fazla bağımlı değişkene tek bir bağımsız değiş̧kenin etki ettiği durumlarda kullanılmaktadır (Kalayc1, 2010: s. 155). Bu çalışmada hile üç alt boyutuyla birlikte incelendiği için (bağımlı değişken sayısı birden fazla) verilerin analizinde tek yönlü manova kullanılmıştır.

\subsubsection{Güvenilirlik Analizi}

Ölçeğin güvenilirliğini tespit etmek amacıyla güvenilirlik analizi yapılmıştır. Yapılan analiz sonucunda elde edilen Cronbach Alfa değerinin 0,787'dir. Bu değer ölçeğin güvenilir olduğunu göstermektedir.

\subsubsection{Hile İle İlgili Senaryolara Ait Tanımsal İstatistikler}

Kullanılan ölçekte üç farklı hile türü ile ilgili senaryolara yer verilmiştir. Senaryo 1 ve Senaryo 4 varlık usulsüzlügü̈; Senaryo 2 ve Senaryo 5 yolsuzluk; Senaryo 3 ve Senaryo 6 ise mali tablo hilesi ile ilgilidir. Söz konusu senaryolarda verilen kararlara katılma derecelerinin ve senaryolardaki durumları raporlama eğilimi değerlendirme derecelerinin ortalamaları ve standart sapmaları Tablo 1'de verilmiştir. Hile karşısındaki tutumların yanı sıra raporlama eğilimlerinin belirlenmesi için de her senaryo ile ilgili raporlama eğilimlerinin cevaplanması istenmiş ve elde edilen verilerden yola çıkılarak farklı hile türleri karşısındaki raporlama eğilimleri hesaplanmıştır. Tablo 1 incelendiğinde, üç hile türü içerisinde 2,47 ortalama ile mali tablo hilesi değerlendirmelerinin ilk sırada yer aldığ belirlenmiştir.

Sunulan senaryolarda etik dışı olaylar yer almaktadır. Dolayısıyla bu hile türü ile ilgili en yüksek düzeyde etik dışı tutumların öğrenciler tarafından sergilendiği ifade edilebilir. Mali tablo hilesi ile ilgili senaryoları sirasiyla 2,42 ortalama ile varlık usulsüzlügü ve 2,05 ortalama ile yolsuzluk ile ilgili senaryolar takip 
etmiştir. Raporlama eğilimleri ile ilgili ifadeler incelendiğinde öğrencilerin yolsuzluk ile ilgili senaryolarda belirtilen olayları raporlama eğilimlerinin daha yüksek olduğu tespit edilmiştir.

Tablo 1: Ortalama ve Standart Sapma Değerleri

\begin{tabular}{|l|c|c|c|}
\hline & N & Ortalama & $\begin{array}{c}\text { Standart } \\
\text { Sapma }\end{array}$ \\
\hline Senaryo 1 & 170 & 2.45 & 1.44 \\
\hline Rapor 1 & 170 & 3.57 & 1.32 \\
\hline Senaryo2 & 170 & 2.06 & 1.20 \\
\hline Rapor 2 & 170 & 3.84 & 1.22 \\
\hline Senaryo 3 & 170 & 2.25 & 1.24 \\
\hline Rapor 3 & 170 & 3.62 & 1.30 \\
\hline Senaryo 4 & 170 & 2.39 & 1.32 \\
\hline Rapor 4 & 170 & 3.14 & 1.30 \\
\hline Senaryo 5 & 170 & 2.04 & 1.06 \\
\hline Rapor 5 & 170 & 3.48 & 1.20 \\
\hline Senaryo 6 & 170 & 2.68 & 1.33 \\
\hline Rapor 6 & 170 & 3.00 & 1.36 \\
\hline $\begin{array}{l}\text { Hile Türü 1 (HT 1) -Varlik } \\
\text { Usulsüzlüğ̈̈ }\end{array}$ & 170 & 2.42 & 1.05 \\
\hline $\begin{array}{l}\text { Raporlama 1 (R 1)- Varlik } \\
\text { Usulsüzlüğ̈̈ }\end{array}$ & 170 & 3.35 & 1.03 \\
\hline Hile Türü 2 (HT 2) -Yolsuzluk & 170 & 2.05 & 0.87 \\
\hline Raporlama 2 (R 2)- Yolsuzluk & 170 & 3.66 & 0.97 \\
\hline $\begin{array}{l}\text { Hile Türü 3 (HT 3) -Mali Tablo } \\
\text { Hilesi }\end{array}$ & 170 & 2.47 & 0.99 \\
\hline $\begin{array}{l}\text { Raporlama 3 (R 3)- Mali Tablo } \\
\text { Hilesi }\end{array}$ & 170 & 3.31 & 1.06 \\
\hline
\end{tabular}

\subsubsection{Hipotezlerin Test Edilmesi}

Meslek etiği dersini alan/almayan öğrencilerin hile (etik dışı olaylar) ile ilgili tutumlarının farklılaşıp farklılaşmadığını ölçen tek yönlü manova analizi sonuçları Tablo 2'de raporlanmıştır. Söz konusu tablo incelendiğinde verilerin homojen varyansa sahip oldukları (Levene Test $>0.05$ ) görülmektedir. Aynı zamanda meslek etiği dersi alıp almamanın senaryolar karşısındaki tutumlar üzerinde etkiye sahip olduğu da dikkati çekmektedir. En yüksek etki 0.52 katsayısı ile Varlık Usulsüzlüğü hilesine karşı tutumda ve 0.51 ile Mali Tablo Hilesini raporlama davranışında iken en düşük katsayı 0.38 ile Varlık Usulsüzlügünün raporlanması davranışında gözlemlenmiştir. \% 5 anlam düzeyinde meslek etiği dersi alıp almama değişkeni açısından $\mathrm{H}_{1}$ ve $\mathrm{H}_{2}$ hipotezleri bütün hile türleri açısından kabul edilmiştir. Ortalamalara bakıldığında meslek etiği dersini alan öğrencilerin dersi almayan öğrencilere göre etik değerlerden sapma düzeylerinin daha düşük 
olduğu sonucu ortaya çıkmıştır. Benzer şekilde meslek etiği alan öğrencilerin dersi almayan öğrencilere göre, söz konusu etik dışı olaylara karşı daha yüksek raporlama eğilimi sergiledikleri tespit edilmiştir.

Tablo 2: Meslek Etiği Dersini Alan/Almayan Öğrencilerin Hile Tutumlarının Farklılaşıp Farklılaşmadığını Ölçen Tek yönlü Manova Analizi Sonuçları

\begin{tabular}{|c|c|c|c|c|c|c|}
\hline \multirow{2}{*}{$\begin{array}{c}\text { Senaryolar ve } \\
\text { Raporlama } \\
\text { Eğilimleri }\end{array}$} & \multicolumn{2}{|c|}{ Ortalamalar } & \multirow[b]{2}{*}{$\mathrm{F}$} & \multirow[b]{2}{*}{$\mathrm{p}$} & \multirow{2}{*}{$\begin{array}{c}\text { Levene } \\
\text { Test }\end{array}$} & \multirow{2}{*}{$\begin{array}{l}\text { Partialed } \\
\text { Eta } \\
\text { Squared }\end{array}$} \\
\hline & $\begin{array}{l}\text { Meslek Etiği } \\
\text { Dersi Alan } \\
\text { Öğrenciler }\end{array}$ & $\begin{array}{l}\text { Meslek Etiği } \\
\text { Dersi Almayan } \\
\text { Öğgrenciler }\end{array}$ & & & & \\
\hline HT 1 & 2.15 & 2.64 & 9.540 & $0.002 * * *$ & 0.78 & 0.52 \\
\hline R 1 & 3.52 & 3.23 & 3.326 & $0.050 * *$ & 0.48 & 0.38 \\
\hline HT 2 & 1.87 & 2.19 & 5.764 & $0.017 * *$ & 0.73 & 0.46 \\
\hline R 2 & 3.83 & 3.53 & 3.910 & $0.050 * *$ & 0.70 & 0.41 \\
\hline HT 3 & 2.28 & 2.61 & 4.670 & $0.032 * *$ & 0.72 & 0.43 \\
\hline R 3 & 3.58 & 3.09 & 9.320 & $0.003 * * *$ & 0.76 & 0.51 \\
\hline \multicolumn{7}{|c|}{ Hotelling's $\mathrm{T}=3,488, \mathrm{p}=0.003$} \\
\hline \multicolumn{7}{|c|}{ Box'M İstatistiği $>0.05$} \\
\hline
\end{tabular}

Cinsiyetleri itibarıyla öğrencilerin hile ile ilgili tutumlarının farklılaşıp farklılaşmadığını ölçen tek yönlü manova analizi sonuçları Tablo 3'de raporlanmıştır. Söz konusu tablo incelendiğinde verilerin homojen varyansa sahip oldukları (Levene Test $>0.05$ ) görülmektedir. Cinsiyetler itibariyle bazı senaryolar karşısındaki tutumların değiştiği ve buna bağlı olarak cinsiyetin senaryolar karşısındaki tutum üzerinde etkili olduğu görülmektedir (Partial Eta Squared). Söz konusu etkinin cinsiyet açısından sınırlı olduğu da elde edilen katsayılardan yola çıkarak ifade edilmelidir. \% 5 anlam düzeyinde söz konusu değişken açısından $\mathrm{H}_{3}$ ve $\mathrm{H}_{4}$ hipotezleri çeşitli hile türleri (etik dışı olaylar) açısından kabul edilmiştir. Kabul edilen hipotezler mali tablo hilesi ve varlık usulsüzlüğü ile mali tablo hilesi ile ilgili raporlama boyutları ile ilgilidir. Ortalamalar incelendiğinde kız öğrencilerin mali tablo hilesi ile ilgili olarak ortaya konan etik dışı olaya erkek öğrencilere nazaran daha düşük seviyede katıldığı belirlenmiştir. Başka bir ifade ile kız öğrencilerin söz konusu hile türü ile ilgili daha yüksek seviyede etik tutum sergiledikleri ifade edilebilir. Raporlama boyutunda ise, varlık usulsüzlüğü ve mali tablo hilesi ile ilgili etik dişı olay karşısında yine kız öğrencilerin erkek öğrencilere göre daha yüksek seviyede raporlama eğiliminde oldukları tespit edilmiştir. 
Tablo 3: Cinsiyetleri İtibarıyla Öğrencilerin Hile İle İlgili Tutumlarının Farklılaşıp Farklılaşmadığını Ölçen Tek Yönlü Manova Analizi Sonuçları

\begin{tabular}{|c|c|c|c|c|c|c|}
\hline \multirow{2}{*}{$\begin{array}{c}\text { Senaryolar ve } \\
\text { Raporlama } \\
\text { Eğilimleri }\end{array}$} & \multicolumn{2}{|c|}{ Ortalamalar } & \multirow[b]{2}{*}{$\mathrm{F}$} & \multirow[b]{2}{*}{$\mathrm{p}$} & \multirow{2}{*}{$\begin{array}{c}\text { Levene } \\
\text { Test }\end{array}$} & \multirow{2}{*}{$\begin{array}{l}\text { Partialed } \\
\text { Eta } \\
\text { Squared }\end{array}$} \\
\hline & Erkek Öğrenci & Kız Öğrenci & & & & \\
\hline HT 1 & 2.42 & 2.42 & 0.000 & 0.986 & 0.10 & 0.00 \\
\hline$R 1$ & 3.16 & 3.52 & 5.266 & $0.023 * *$ & 0.15 & 0.08 \\
\hline HT 2 & 2.09 & 2.01 & 0.325 & 0.570 & 0.13 & 0.01 \\
\hline R 2 & 3.63 & 3.69 & 0.143 & 0.706 & 0.12 & 0.01 \\
\hline HT 3 & 2.63 & 2.32 & 4.322 & $0.039 * *$ & 0.18 & 0.11 \\
\hline$R 3$ & 3.08 & 3.51 & 7.294 & $0.008^{* * * *}$ & 0.24 & 0.23 \\
\hline \multicolumn{7}{|c|}{ Hotelling's $T=2.769, p=0.014$} \\
\hline Box'M Istatisti & $>0.05$ & & & & & \\
\hline
\end{tabular}

Çalışmada öğrencilerin etik dışı olaylar karşısındaki tutumları ve rapor etme eğilimleri arasında bir ilişkinin olup olmadığının belirlenmesi ve ortaya konulan hipotezin test edilmesi amacıyla korelasyon analizi yapılmıştır. Korelasyon analizi kapsamında elde edilen bulgular Tablo 4'de raporlanmıştır. Bu noktadaki beklenti, senaryodaki davranışların onaylanma düzeyi ile raporlama eğiliminin ters yönlü bir ilişki içinde olmasıdır. Elde edilen sonuçlar da söz konusu beklentiyi desteklemektedir. Bütün etik dışı durumlar için istatistiksel olarak anlamlı düzeyde negatif yönlü bir ilişki olduğu tespit edilmiştir. $\mathrm{Bu}$ nedenle $\mathrm{H}_{5}$ hipotezi bütün senaryolar için kabul edilmiştir. Ayrıca çeşitli hile türleri arasında da farklı düzeylerde ilişki tespit edilmiştir. Etik dışı senaryolara katılım düzeyi azaldıkça raporlama eğilimi artış göstermektedir.

\section{Tablo 4: Öğrencilerin Hile Algısı ve Raporlama Eğilimi Arasındaki İlişki (Korelasyon Analizi)}

\begin{tabular}{|l|c|c|c|c|c|c|c|}
\hline \multicolumn{2}{|c|}{} & HT 1 & R 1 & HT 2 & R 2 & HT 3 & R 3 \\
\hline HT 1 & Korelasyon Değeri & 1 & & & & & \\
\hline R 1 & Korelasyon Değeri & $-0.42^{* * *}$ & 1 & & & & \\
\hline HT 2 & Korelasyon Değeri & $0.42^{* * *}$ & -0.15 & 1 & & & \\
\hline R 2 & Korelasyon Değeri & $-0.16^{* *}$ & $0.42^{* * *}$ & $-0.37^{* * *}$ & 1 & & \\
\hline HT 3 & Korelasyon Değeri & $0.43^{* * *}$ & $-0.17^{* *}$ & $0.36^{* * *}$ & $-0.30^{* * *}$ & 1 & \\
\hline R 3 & Korelasyon Değeri & -0.04 & $0.39^{* * *}$ & -0.11 & $0.49^{* * *}$ & $-0.46^{* * *}$ & 1 \\
\hline
\end{tabular}

\section{Sonuç ve Öneriler}

Meslek etiği ve öğrenciler üzerindeki etkileri hemen hemen her disiplinde kendine inceleme alanı bulan bir konudur. Meslek grupları açısından da farklı boyutlarıyla ele alınarak incelenen meslek etiği konusu, işletme ve özelinde muhasebe ve denetim alanında akademik literatürde önemli bir yere sahiptir. Tarihsel açısından değerlendirildiğinde, küresel boyutta ortaya çıkan ekonomik skandallar meslek etiği konusunu yeniden tartışmaya açmakta ve konunun gündemde kalmasına 
neden olmaktadır. Bu çalışmada da meslek etiği, üniversitelerde verilen meslek etiği dersi kapsamında ele alınmıştır. Bu doğrultuda geleceğin profesyonelleri olarak değerlendirilen öğrencilerin karşılaştıkları olaylar karşısında sergiledikleri etik davranışlar üzerinde meslek etiği dersinin etkisinin olup olmadığ değerlendirilmiştir. Bu kapsamda incelemeye dahil edilen öğrenciler meslek etiği dersi alıp almamalarına göre gruplandırılarak dersin öğrenci davranışları üzerindeki etkilerinin ortaya konulması amaçlanmıştır.

Çalışmadan elde edilen bulgular üç başlık altında değerlendirilebilir. Birincisi, meslek etiği dersi alan ve almayan öğrencilerin kendilerine sunulan varlık usulsüzlüğü, yolsuzluk ve mali tablo hilelerine ait etik değerlendirmeleri ve raporlama eğilimleri farklılaşmaktadır. Bu kapsamda çalışmadan elde edilen bulgulara göre meslek etiği dersi alan öğrencilerin almayan öğrencilere göre senaryolarda yer alan olaylara karşı daha etik davranışlar sergiledikleri ve olayları raporlama eğilimlerinin daha yüksek olduğu görülmektedir. Buradan yola çıkarak verilen meslek etiği dersinin öğrencilerin etik davranışları ve etik bulmadıkları olayları raporlama eğilimleri üzerinde etkili olduğu ifade edilebilir.

İkinci aşamada öğrenciler cinsiyetlerine göre gruplandırılarak senaryolar karşısında etik değerlendirmeleri ve raporlama eğilimlerinin farklılaşıp farklılaşmadığı incelenmiştir. Bu kapsamda elde edilen bulgulara göre kız öğrencilerin erkek öğrencilere göre varlık usulsüzlüğü raporlama eğilimleri ve mali tablo hilelerine karşı etik değerlendirme ve raporlama eğilimlerinin farklılaştığı görülmektedir. Bu kapsamda belirli boyutlar ve senaryolar karşısında kız öğrencilerin erkek öğrencilere göre etik toleranslarının daha düşük olduğu ve etik dışı olarak değerlendirdikleri olayları raporlama eğilimlerinin daha yüksek olduğu ifade edilebilir.

Üçüncü aşamada ise inceleme kapsamındaki öğrencilerin senaryolar karşısındaki etik değerlendirmeleri ve olayları raporlama eğilimleri arasında bir ilişki olup olmadığ incelenmiştir. Elde edilen bulgulara göre öğrencilerin bir senaryoyu etik dışı olarak değerlendirmeleri ile raporlama eğilimleri arasında anlamlı ilişki tespit edilmiştir. $\mathrm{Bu}$ kapsamda öğrencilerin bir olayı etik dişı olarak değerlendirdiklerinde, olaya katılmama düzeyleri arttıkça söz konusu olayı raporlama eğilimleri de artmaktadır.

Çalışma kapsamında elde edilen sonuçların meslek etiği dersinin öğrencilerin karşılaşabilecekleri olası olaylar karşısındaki etik değerlendirmeleri ve bu kapsamda değerlendirilen olayları raporlama eğilimleri üzerinde etkili olduğu sonucuna ulaşılmıştır. Aynı zamanda literatürdeki bulgulara benzer olarak (Dönmez ve Karausta, 2011; Eweje ve Brunton, 2010; Gill, 2010; Hacihasanoğlu ve Karaca, 2015) kız öğrencilerin erkek öğrencilere göre etik toleransının daha düşük olduğu, diğer bir ifade ile olaylara karşı daha etik yaklaştıklarını destekleyen bulgular da elde edilmiştir. 
Çalışmanın kısıtlı bir örneklem ile (170 öğrenci) yapılmış olması çalışmanın sınırlılı̆gı olarak ifade edilebilir. Gelecek çalışmalarda örneklem düzeyinin arttırılmasının hatta üniversiteler arası karşılaştırma yapmaya olanak tanıyacak bir kurguda yenilenmesinin faydalı olacağı düşünülmektedir. Diğer taraftan çalışma kapsamında incelenen konunun yalnızca öğrenciler açısından değil, aynı zamanda meslek mensuplarını da kapsayacak şekilde gerçekleştirilmesinin elde edilen sonuçlara daha geniş bir bakış açısı kazandıracağı değerlendirilmektedir.

\section{Kaynakça}

Adkins, N., ve Radtke, R. R. (2004). Students' and faculty members' perceptions of the importance of business ethics and accounting ethics education: Is there an expectations gap? Journal of Business Ethics, 51(3), 279-300.

Ahmed, M. M., Chung, K. Y., ve Eichenseher, J. W. (2003). Business students' perception of ethics and moral judgment: A cross-cultural study. Journal of Business Ethics, 43(1), 89-102.

Ahmad, N. L., ve Ahmed, H. (2017). The Acceptability and impact of sharia foundation of Islamic ethics in accounting education. International Journal of Academic Research in Business and Social Sciences, 7(2), 494-506.

Baird, J. E. Ve Zelin, R. (2008), Understanding employee perceptions of fradulent activitiesand their propensity to report those activities using anonymous tip lines: the influence of fraud type, propetrator gender, and observer demographics, Southern Business Review, 33, 1-14.

Cameron, R. A., ve O'leary, C. (2015). Improving ethical attitudes or simply teaching ethical codes? The reality of accounting ethics education. Accounting Education, 24(4), 275-290.

Dellaportas, S., Cooper, B. J., ve Leung, P. (2006). Measuring moral judgement and the implications of cooperative education and rule-based learning. Accounting \& Finance, 46(1), 53-70.

Dönmez, A. ve Karausta, T. (2011). Çalışanların mesleki hile algısı ve ihbar hattı kullanarak rapor etme eğilimleri üzerine Akdeniz Üniversitesi Iktisadi Idari Bilimler Fakültesinde yapılan bir araştırma, Mali Çözüm Dergisi, 104, 1741.

Eweje, G., ve Brunton, M. (2010). Ethical perceptions of business students in a New Zealand university: do gender, age and work experience matter? Business Ethics: A European Review, 19(1), 95-111. 
Gill, S. (2010). Is gender inclusivity an answer to ethical issues in business? An Indian stance. Gender in Management: An International Journal, 25(1), 3763.

Hacihasanoğlu, T. ve Karaca N. (2015). Potansiyel muhasebe meslek mensuplarının hile algısı üzerine Bozok Üniversitesi'nde yapılan bir araştırma. Niğde Üniversitesi İktisadi ve İdari Bilimler Fakültesi Dergisi, 8(1), 117-130.

Hiltebeitel, K. M., ve Jones, S. K. (1992). An assessment of ethics instruction in accounting education. Journal of Business Ethics, 11(1), 37-46.

Jennings, P., ve Marriott, N. (2013) Ethics in accounting. (Erişim tarihi: $13 / 01 / 2018)$

https://www.heacademy.ac.uk/system/files/ethics_in_accounting_report.pdf

Kalayc1, Ş. (2010). SPSS uygulamalı çok değişkenli istatistik teknikleri (Vol. 5). Ankara, Turkey: Asil Yayın Dağıtım.

Klimek, J., ve Wenell, K. (2011). Ethics in accounting: an indispensable course? Academy of Educational Leadership Journal, 15(4), 107.

Kurnaz, N. ve Gümüş, Y. (2010). Muhasebe bölümü öğrencilerinin muhasebe mesleği ile ilgili etik dışı davranışlara ilişkin algı analizi: Dumlupınar Üniversitesi Uygulamalı Bilimler Yüksekokulu örneği, Muhasebeve Finansman Dergisi, 46, 157-174.

Liu, C., Yao, L. J., ve Hu, N. (2012). Improving ethics education in accounting: Lessons from medicine and law. Issues in Accounting Education, 27(3), 671-690.

Mcphail, K., ve Walters, D. (2009). Accounting and business ethics: An introduction: Routledge.

Şımga-Mugan, C. ve Önkal-Atay, D. (2003). Contextual effects on ethical sensitivity and penalty judgments, Teaching Business Ethics, 7(4), 341-363.

Uyar, S., Kahveci, A. ve Yetkin M. (2015). Öğrencilerin muhasebe meslek etiği algıs1: ALTSO Meslek Yüksekokulu örneği, Niğde Üniversitesi İktisadi ve İdari Bilimler Fakültesi Dergisi, 8(2), 237-247.

Yarahmadi, H., ve Bohloli, A. (2015). Ethics in accounting. International Journal of Accounting and Financial Reporting, 5(1), 356-360. 
Y1ldız, G. (2011). Muhasebe mesleğinde meslek etiği ve Kayseri il merkezinde bir uygulama. Erciyes Üniversitesi İktisadi ve İdari Bilimler Fakültesi Dergisi,36, 155-178.

http://www.tdk.gov.tr/index.php?option=com_bts\&view=bts\&kategori1=veritbn \&kelimesec=118065 (TDK, Erişim tarihi: 10.01.2018)

http://www.tdk.gov.tr/index.php?option=com_gts\&arama=gts\&guid=TDK.GTS.5 a6c8d4a4b15e1.27366686 (TDK, Erişim Tarihi: 10.01.2018)

ACFE, 2016 (Erişim Tarihi: 07.01.2018)

https://www.acfe.com/rttn2016/docs/2016-report-to-the-nations.pdf

ACFE, 1996 Erişim tarihi (26.03.2018)

http://www.acfe.com/uploadedfiles/acfe_website/content/documents/1996-rttn.pdf 


\title{
The Effects Of Business Ethics Course On Students' Fraud Attitudes And Reporting Tendencies
}

\author{
Extended Abstract
}

\section{Introduction}

Financial statements prepared by companies for the purpose of providing information to financial statement users should be presented reliably and fairly. However, such a presentation is often not possible due to various reasons. Business ethics and fraud perception take an important place among that reasons. The perception of ethics and fraud of managers and employees cause the financial statement presentations speciously. Especially in the beginning of the 2000s, corporate bankruptcies, resulting from accounting scandals, caused the question of ethics and fraud in the accounting profession to be questioned and reviewed. Given the economic scandals and the negative consequences, the need for accountants with high ethical values has become important, which has led to discussion of ethics issues within the class and curriculum. In general, the inclusion of ethics education in classroom and curriculum is essential to the students' ethical development, and therefore the need to incorporate them into the educational process is expressed in the literature. In this respect, the aim of this study is to examine whether the attitudes and reporting tendencies of the students who did or did not take the course of "business ethics" in undergraduate education were differentiated in relation to ethical scenarios.

\section{Method}

There are many variables that affect students' understanding of professional ethics and perception of fraud. One of these variables is the business ethic course that students take this course at the undergraduate level. It has been found that, in many studies conducted at national and international level, the education of the students about the business ethics they have received has had positive results. From this point of view, the main purpose of this study is to show whether the attitudes and reporting tendencies of the students who take the course of the business ethics and the students who do not take this course will be differentiated.

The sample of the study consist of students in the business administration department of Bozok University. Primary data have been collected by using the questionnaire method. Since the study has been conducted within the framework of determining the attitudes and reporting tendencies exhibited related to financial events, the students who take accounting courses have been identified as the target group. A total of 250 questionnaires have been applied to final year students in order to reach the highest number of sample in the study. Initially, 250 questionnaires were applied and 80 of them were evaluated as not suitable for use in analysis. Therefore, 170 questionnaires were included in the analysis. 75 of the 170 surveys belong to the students who took the course of the business ethics and 95 of them belong to the students who did not take the course. The final year students who are studying in the department of management are divided into two groups in order to measure and compare the perceptions related to business ethics and fraud. In the first group, there are students who are studying in the last year and who did not take the course of business ethics yet. In the second group, final year students who took business ethics course took place. The students in the second group have been primarily trained in the basic subjects covered by the business ethics course. In addition to these trainings, students have been shown the film "Enron: The Smartest Guys in the Room" about Enron case, one of the biggest accounting scandals of history. As a result of the trainings and activities, it is ensured that the students who take the business ethics course should be conscious about the business ethics. 


\section{Results and Discussion}

The findings can be evaluated under three main topics. First, there is a difference between the students who take and do not take courses in ethics. Also it is determined that the ethical evaluations and reporting tendencies different between groups with regards to corruption, asset irregularity and misrepresentation of financial statements presented. According to the findings, it is stated that the students who take the business ethics course show more ethical behaviors and tendency to report the events in the scenario than the students who do not take the course. It can be said that the business ethics course is influential on the students' ethical perception and tendency to report events that they do not find ethic.

In the second stage, the students have been grouped according to their gender and examined whether the ethical evaluations and reporting tendencies differed in relation to scenarios. According to the findings obtained in this context, it is observed that the tendency of female students to report asset irregularities and ethical evaluation are different from male students. In this context, it can be stated that female students have lower ethical tolerances than male students and that they tend to report events they evaluated unethical against certain scenarios.

In the third step, it is examined whether there is a relationship between the ethical evaluations against the scenarios and the tendency to report events. According to the findings, there is a significant relationship between the students' evaluations of a scenario as unethical and the reporting tendencies. In this context, when students evaluate an event as unethical, the tendency to report the event increases as the level of disagree increases.

\section{Conclusion}

According to the findings of the study, it has been observed that the business ethics course effects on the ethical evaluations of the possible events that students may experience and their tendency to report these events. At the same time, findings similar to the literature have been found supporting the lower ethical tolerance of female students compared to male students. The study has been conducted with a limited sample (170 students) and it can be expressed as the limit of the study. It is thought that it will be useful to increase the number of sample in future studies and to repeat the study in a structure that will allow comparison between universities. On the other hand, it is considered that the expansion of the subject studied in the scope of the study, including the members of the profession, will give a broader perspective on the results obtained. 